Analysis

\title{
Policy resistance to harm reduction for drug users and potential effect of change
}

BMJ 2010; 341 doi: http://dx.doi.org/10.1136/bmj.c3439 (Published 13 July 2010) Cite this as: BMJ 2010;341:c3439

- Article

- Related content

- Metrics

- Responses

- Peer review

-

Tim Rhodes, professor of public health sociology1, Anya Sarang, consultant researcher2, Peter Vickerman, senior lecturer of mathematical epidemiology13, Matthew Hickman, professor of public health and epidemiology 3

\section{Author affiliations}

Correspondence to: T Rhodes tim.rhodes@Ishtm.ac.uk Accepted 2 June 2010

Despite good evidence for its effectiveness in HIV prevention, countries such as Russia remain resistant to harm reduction. Tim Rhodes and colleagues show the obstacles to and potential benefits of changing policy on opiate substitution treatment

The health harms of injecting drug use include HIV, hepatitis $\mathrm{C}$, bacterial infections, overdose, and substantial excess mortality. An estimated 16 million people inject drugs worldwide, 3 million of whom live in eastern Europe.1 Around 1.5 million people are infected with HIV in eastern Europe, with most infected through injecting drug use.2 The largest European epidemics are those in the Russian Federation and Ukraine, where over a third of injecting drug users are thought to be HIV positive.12 One contributing factor is policy resistance to harm reduction.

\section{Harm reduction}

Harm reduction encompasses interventions and policies that seek primarily to reduce the harms of drug use without necessarily requiring abstinence from drug use. The Council of the European Union, World Health Organization, and United Nations Joint Programme on HIVIAIDS recommend a comprehensive package of harm reduction services for people who inject drugs, including programmes providing easy access to clean needles and syringes, opioid substitution treatment, and antiretroviral drugs for HIV.3 Access to opioid substitutes and syringe distribution programmes can reduce risky injecting practices and incidence of HIV.4 56 Opioid substitution also reduces deaths from overdose, drug related mortality, and offending. Access to antiretroviral HIV treatment improves mortality and morbidity among injecting drug users. 7

A critical factor determining the effect of interventions is their coverage among target populations. 8 Intervention coverage varies widely globally but is especially low in eastern Europe, where only around 
$10 \%$ of injecting drug users have access to syringe exchange programmes and, at best, $1 \%$ have access to opioid substitutes.9 The UN made providing "near universal access" to harm reduction services for those who need them by 2010 a global priority. 3 However, the availability and accessibility of interventions depends on environmental and policy factors, and sufficient coverage is unlikely without policy, legal, or social change.10 11

Moreover, harm reduction interventions are more effective when they are combined.10 For example, a cohort study in Amsterdam showed that "full participation" in combined syringe exchange and opioid substitution programmes reduced incidence of HIV by two thirds, whereas participation in syringe exchange alone was not associated with a reduction in HIV incidence.12 Initiation and adherence to antiretroviral HIV treatment also improves when access to opioid substitutes is good.13 The enhanced effects of combining opioid substitution with syringe distribution and antiretroviral HIV treatment are particularly relevant for countries with large HIV outbreaks.

\section{Policy resistance}

Although harm reduction is central to European Union policies, some countries are resistant to this approach. The United States, for instance, has long acted as a force of resistance to harm reduction on the global stage and nationally. It has emphasised a "war on drugs" policy, which, until recently, promoted federal or state restrictions on the funding and evaluation of syringe distribution programmes.14 In Russia, there is also strong resistance to harm reduction. The use of methadone and buprenorphine in treating opioid dependence is legally prohibited, syringe distribution programmes lack adequate coverage and political support, and the primary emphasis on law enforcement and the criminalisation of drug use create an environment that can exacerbate HIV risk and other harms.

The record of a recent meeting of the Security Council of the Russian Federation, attended by the president (Dmitry Medvedev), prime minister (Vladimir Putin), minister of health (Tatyana Golikova), director of the Serbsky National Research Centre for Social and Forensic Psychiatry (Tatyana Dmitrieva), and director of the Federal Drug Control Service (Viktor Ivanov), captures Russia's policy resistance to harm reduction.15 Tatyana Dmitrieva, speaking in her role as the deputy chair of the International Narcotic Control Board, said: "Russia is against the introduction of harm reduction policy. This is a really very difficult topic because we are facing very powerful pressure which undoubtedly has political implications ... We are not for harm reduction, we are for supply reduction."

At the same meeting, the minister of health said Russia is "categorically against" providing "substitution treatment for drug addicts" and that "the distribution of sterile needles and syringes stimulates social tolerance of drug addicts and violates the Criminal Code of the Russian Federation. Unfortunately, purchasing sterile needles and syringes is not a problem in the Russian Federation. Today, the price for sterile syringes is much lower than the price for the cheapest narcotic drugs available."

Russia prohibits the use of methadone and buprenorphine (or other opiates) to treat opioid dependence, despite international pressure and good evidence supporting opioid substitution treatment.4 5 WHO defines it as an "essential medicine," and substitutes are prescribed to over 650?000 people in Europe. Treatments for opioid users in Russia are instead modelled on alcohol detoxification, oriented to alleviating short term symptoms of withdrawal, and have high relapse rates.16 17 With heroin more accessible than substitution treatment, opportunities for preventing HIV infection are reduced.

Russia has only about 75 needle and syringe programmes for its two million injecting drug users. 1 Such 
programmes do not "violate" the national criminal code, as the health minister suggested, but one reason for their poor coverage remains a fear that distribution of syringes may be interpreted as promoting drug use under article 230 of the Criminal Code (1996). In 2003, an amendment to this article exempted the provision of health equipment, subject to the agreement of regional representatives of the Ministry of Health and Federal Drug Control Service. Formal instructions on this agreement have yet to be instituted, even though studies do not show that syringe distribution programmes encourage drug use or "social tolerance" of it.5 10 If it was not for the availability of cheap needles and syringes from pharmacies, HIV rates could be worse.

In the absence of national funding for HIV prevention for injecting drug users, the Global Fund has continued its support of 22 pilot programmes. Evaluation of these has estimated that they averted $37 ? 000$ HIV cases, 18 with surveys in 2006 and 2008 finding that injecting drug users who participated in the programmes halved their risk of HIV infection compared with those who did not participate.19

\section{Roots of resistance}

Aside from Russia, only three countries in the European and central Asian region do not provide opioid substitution treatment: Tajikistan, Turkmenistan, and Uzbekistan.9 20 Uzbekistan discontinued its programme for about 150 users last year. Tajikistan plans to pilot opioid substitution treatment, partly to prevent jeopardising international health funding.20 Other programmes in central Asia operate as fragile pilots with little evidence of meaningful expansion. One of the largest is in Kyrgyzstan, providing treatment to about 950 people. The programme was threatened with closure in 2009 , and like many others in the region relies heavily on international funding.

Resistance to introducing or scaling-up opioid substitution treatment in former Soviet countries partly stems from concerns about the adverse economic effects of changes to existing drug treatment systems alongside concerns that current systems would be unable to prevent substitute medicines (such as methadone or buprenorphine) entering the illicit market or safely monitor their use.17 20 More fundamentally, resistance to substitution treatments is grounded in the history, teaching, and mentality of "narcology," a subdivision of Soviet criminal psychiatry with close links to state law enforcement. Narcology conceives of treatment from addiction in terms of abstinence17 21 and is closely linked with the Serbsky Central Research Institute of Social and Forensic Psychiatry, once infamous for using psychiatric medicines for state ordered "treatment" of Soviet dissidents. Narcologists have opposed the use of methadone in opioid treatment as a "vicious practice," as one step removed from "legalising" drug use, as a failing intervention of the West, and, most importantly, as a failure to deal with the criminality of drug users.1722

Resistance to opioid substitution thus has a cultural historical context. Nevertheless, change is needed since drug policies that emphasise repressiveness through law enforcement are linked with higher health risks.14 In Russia, administrative and criminal codes relating to drug use and possession combine with aggressive police surveillance, resulting in the mass imprisonment of drug users and a prison system linked to outbreaks of HIV infection.23 Intense police surveillance can make drug users reluctant to seek help or carry sterile needles and syringes for fear of arrest, fine, or detention, and studies show that drug users who have contact with the police, from arrest through to assault, may be more likely to share syringes.112425

\section{Benefits of change}




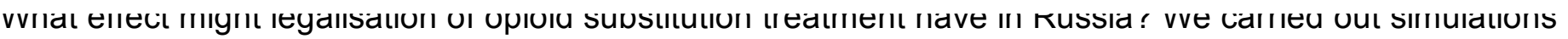
using a dynamic model of HIV transmission in injecting drug users for different types of HIV epidemic in Russia. We estimated the effect of current syringe distribution programmes, optimistically assuming that they reduce the average syringe sharing frequency of all reached participants by $75 \% .6$ Studies suggest that opioid substitution treatment can reduce risk of HIV infection by $60-84 \%$, and we used this range in our simulations.4 A full description of the model is available on bmj.com.

The figure shows that the current coverage of syringe distribution programmes in Russia (10\%) is unlikely to reduce HIV incidence among injecting drug users by more than $15 \%$ over five years. Conversely, increasing the coverage of opioid substitution treatment from $0 \%$ to $10 \%, 25 \%$, or $50 \%$ could decrease incidence by $21 \%$ (90\% confidence interval $14 \%$ to $34 \%$ ), $34 \%$ (23\% to $51 \%$ ), or $55 \%$ ( $40 \%$ to $71 \%$ ), respectively. Most of the uncertainty in the projections is due to uncertainty about the effect of opioid substitution and the baseline HIV prevalence of the different epidemics modelled. For example, at a prevalence of $15 \%$ (which best fits many Russian cities including Moscow), $25 \%$ coverage of opioid substitution could decrease HIV incidence by $44-53 \%$ over five years. However, if HIV prevalence is $40 \%$ or $60 \%$ (similar to that in Russian cities such as Irkutsk or Ekaterinburg), the resulting decrease in HIV incidence is reduced to $33-43 \%$ or $24-38 \%$, respectively.
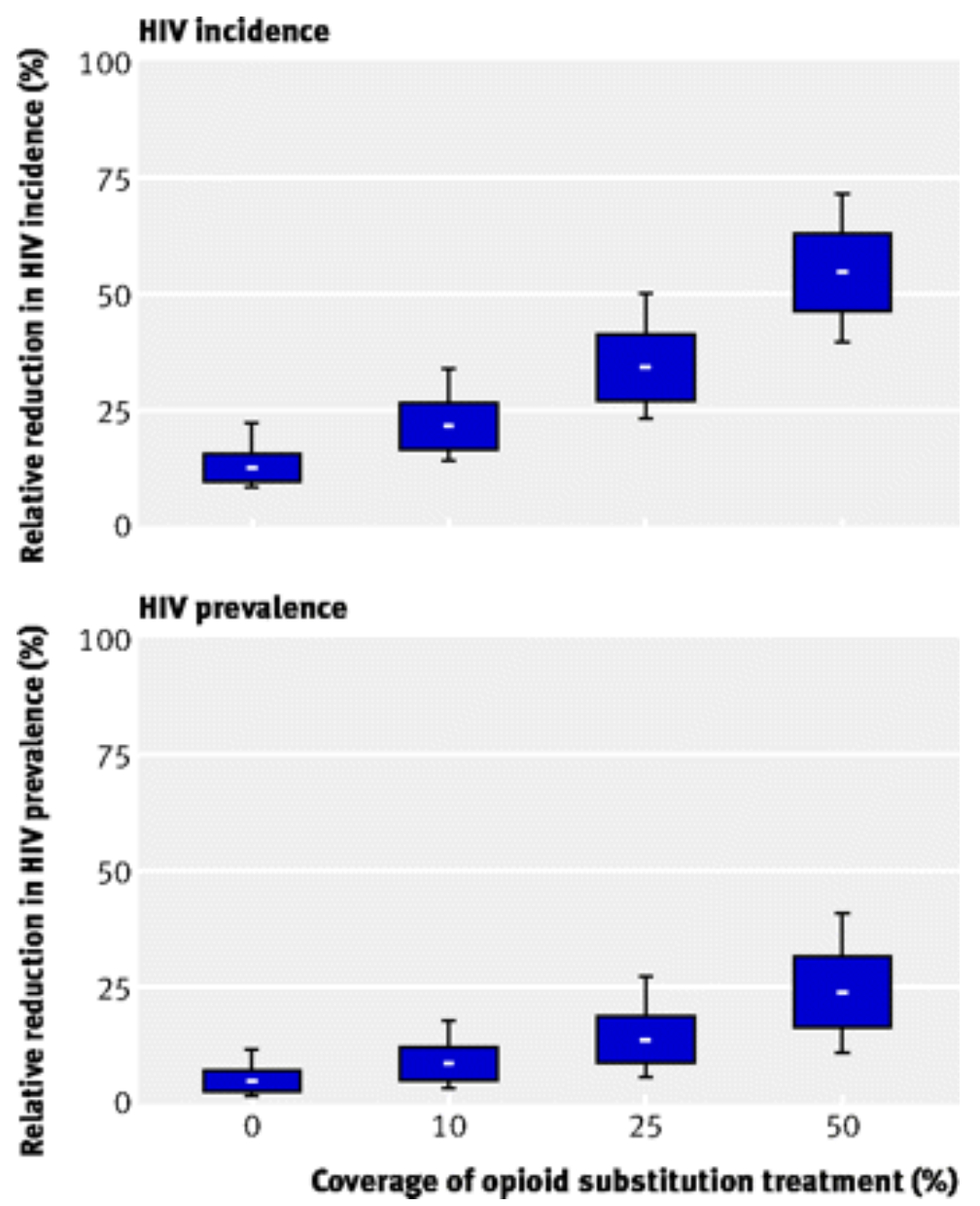

Effect of different coverage of opiate substitution treatment on HIV incidence and prevalence after five years assuming coverage of needle and syringe exchange programmes stays at $10 \%$. Bounds for each scenario show the range of effect estimates for different HIV epidemics modelled (whiskers are $10 \%$ and $90 \%$ percentiles, box limits are $25 \%$ and $75 \%$ percentiles, and lines are median estimates) 
Changing HIV prevalence takes longer (figure $\mathbb{1}$, bottom). Nevertheless, increasing opioid substitution to $25 \%$ or $50 \%$ could reduce prevalence by $14 \%$ (6\% to $28 \%$ ) or $24 \%$ (12\% to $41 \%)$ after five years. Again, the effect depends on baseline HIV prevalence, with $25 \%$ coverage reducing prevalence by $25-31 \%, 16-$ $21 \%$, and $10-17 \%$ for baseline prevalences of $15 \%, 40 \%$, and $60 \%$ respectively (see bmj.com).

\section{Conclusion}

Opioid substitution is a critical component of HIV prevention and treatment.3 4101213 Our projections suggest that Russia could substantially reduce the incidence of HIV infection if it permitted the use of opioid substitution treatment. The benefits could be even greater than we estimate as the model does not include changes in offending, or antiretroviral HIV treatment. The prohibition, by federal law or otherwise, of opioid substitution treatment limits rights of access to evidence-based health care, as championed by the UN and other international agencies. 3 The roots of resistance to harm reduction in Russia are complex, and show why efforts to bring about structural changes in national laws and policies should be at the forefront of global efforts to scale-up HIV prevention.

\section{Notes}

Cite this as: BMJ 2010;341:c3439

\section{Footnotes}

- We thank Alisher Latypov, Natalia Bobrova, and the BMJ reviewers for their comments. The Centre for Research on Drugs and Health Behaviour at London School of Hygiene and Tropical Medicine acknowledges funding support from the UK Department of Health.

- Contributors and sources: The authors are involved in researching and working towards the development of public health approaches in HIV prevention among injecting drug users, including in Russia. TR leads social science studies on HIV prevention and treatment. AS works for a foundation that advocates for improved access to health services for drug users in Russia. PV is a mathematical modeller, and $\mathrm{MH}$ a public health epidemiologist. All contributed to the concept, analysis. and writing of this article, with PV and MH leading the modelling. TR is guarantor.

- Competing interests: None declared.

- Provenance and peer review: Not commissioned; externally peer reviewed.

\section{References}

1. $\downarrow$ Mathers BM, Degenhardt LJ, Phillips B, Wiessing L, Strathdee SA, Wodak A, et al. Global epidemiology of injecting drug use and HIV among people who inject drugs. Lancet2008;372:1733-45. CrossRef Medline

$\underline{\text { Web of Science }}$

2. UNAIDS. AIDS enidemic undate. UNAIDS. WHO. 2009 
3. $\downarrow$ United Nations General Assembly. Political declaration on HIVIAIDS. Resolution 60/262 adopted by the United Nations General Assembly. United Nations, 2006.

4. $\downarrow$ Gowing L, Farrell M, Bornemann R, Sullivan L, Ali R. Substitution treatment of injecting opioid users for prevention of HIV infection. Cochrane Database Sys Rev2008;2:CD004145.

5. $\downarrow$ Institute of Medicine. Preventing HIV infection among injecting drug users in high-risk countries: an assessment of the evidence. National Academy of Sciences, 2007.

6. $\lrcorner$ Des Jarlais DC, Kling R, Hammett TM, Ngu D, Liu W, Chen Y,et al. Reducing HIV infection among new injecting drug users in the China-Vietnam cross border project. AIDS2007;21(suppl 8):S109-14. CrossRef Medline Web of Science

7. $\downarrow$ Lert F, Kazatchkine M. Antiretroviral HIV treatment and care for injecting drug users: an evidence based overview. Int J Drug Policy2007;18:255-61. Medline

8. $\downarrow$ Vickerman P, Hickman M, Rhodes T, Watts C. Model projections on the required coverage of syringe distribution to prevention HIV epidemics among injecting drug users. J AIDS2006;42:255-61.

9. $\downarrow$ Mathers B, Degenhardt L, Ali H, Wiessing L, Hickman M, Mattick RP, et al. HIV prevention, treatment and care services for people who inject drugs: a systematic review of global, regional, and national coverage. Lancet 2010;375:1014-28. CrossRef Medline Web of Science

10. $\downarrow$ Degenhardt L, Mathers B, Vickerman P, Rhodes T, Latkin C, Hickman M. HIV prevention for people who inject drugs: why individual, structural, and combination approaches are required. Lancet2010 (forthcoming). doi:10.01553/S0140-6736(10)60742-8.

11. $\downarrow$ Strathdee SA, Hallet TB, Bobrova N, Rhodes T, Booth R, Abdool R, et al. HIV and risk environment for injecting drug users: the past, present, and future. Lancet 2010 (forthcoming). doi: $10.01608 /$ S01406736(10)60743-X.

12. $\downarrow$ Van Den Berg C, Smit C, Van Brussel G, Coutinho RA, Prins M. Full participation in harm reduction programmes is associated with decreased risk for human immunodeficiency virus and hepatitis $C$ virus: evidence from the Amsterdam cohort studies among drug users. Addiction2007;102:1454-62. CrossRef Medline Web of Science

13. $\downarrow$ Roux P, Carrieri MP, Villes V, Dellamonica P, Poizot-Martin I, Ravaux I, et al. The impact of methadone or buprenorphine treatment and ongoing injection on highly active antiretroviral therapy (HAART) adherence.

Addiction 2008;103:1828-36. CrossRef Medline Web of Science

14. $\downarrow$ Wood E, Werb D, Marshall B, Montaner JSG, Kerr T. The war on drugs: a devastating public-policy disaster. Lancet 2009:373:989-90.

15. $\downarrow$ Security Council of the Russian Federation. Stenogram of the meeting on improving the state policy in combating drugs. Kremlin, September 2009.

16. $\downarrow$ Human Rights Watch. Rehabilitation required: Russia's human rights obligation to provide evidence-based drug dependence treatment. Human Rights Watch, 2007.

17. $\downarrow$ Elovich R, Drucker E. On drug treatment and social control: Russian narcology's great leap backwards. Harm Reduction J2008;5:23. CrossRef

18. $\downarrow$ Plavinsky SL. Assessing the effectiveness of the GLOBUS project. GLOBUS Project Newsletter2008;7.

19. $\downarrow$ Plavinsky SL. Sexually transmitted infections, HIV infection, and effectiveness of harm reduction programs in Russia. GLOBUS Project, 2009.

20. $\downarrow$ Latypov A. Opioid substitution therapy in Tajikistan: Another perpetual pilot? Int J Drug Policy2010 Feb 23 [pub ahead of print]. 
Rev2006;11:82-4

22. $\downarrow$ Babayan E, Gonopolsky MH. Textbook on alcoholism and drug abuse in the Soviet Union. International Universities Press, 1985.

23. $\downarrow$ Bobrik A, Danishevski K, Eroshina K, McKee M. Prison health in Russia: the larger picture. J Public Health Policy2005;26:30-59. CrossRef Medline Web of Science

24. $\downarrow$ Rhodes T, Mikhailova L, Sarang A, Lowndes CM, Rylkov A, Khutorskoy M, et al. Situational factors influencing drug injecting, risk reduction and syringe exchange in Togliatti City, Russian Federation. Soc Sci Med2003;57:39-54. CrossRef Medline Web of Science

25. $\downarrow$ Rhodes T, Judd A, Mikhailova L, Sarang A, Khutorskoy M, Platt L, et al. Injecting equipment sharing among injecting drug users in Togliatti City, Russian Federation. J AIDS2004;35:293-300. CrossRef

Y Tweet

- $f$ Like 0

- $\mathbf { G } + 1 \longdiv { 0 }$

\section{Article tools}

0 responses

- ERespond to this article

- +Data supplement

- EPrint

- Alerts \& updates

\section{Article alerts}

Please note: your email address is provided to the journal, which may use this information for marketing purposes.

\section{Log in or register:}

$$
\begin{aligned}
& \text { Username * } \\
& \text { Password * } \\
& \text { Log in }
\end{aligned}
$$

$\underline{\text { Register for alerts }}$

(1) If you have registered for alerts, you should use your registered email address as your username - OCitation tools

\section{Download this article to citation manager}

Rhodes Tim, Sarang Anya, Vickerman Peter, Hickman Matthew. Policy resistance to harm reduction for drug users and potential effect of change BMJ 2010; 341 :c3439

- BibTeX (win \& mac)

Download

- EndNote (tagged)

- EndNote 8 (xml) 